\title{
Angiofollicular lymph node hyperplasia with amyloidosis
}

\author{
K.P. West, D.R. Morgan ${ }^{1}$ and I. Lauder \\ Departments of Pathology, University of Leicester, Leicester and 'University of Leeds, Leeds, UK.
}

\begin{abstract}
Summary: Two cases of angiofollicular lymph node hyperplasia are described, one of the solitary plasma cell type the other of the multicentric hyaline vascular type.

Both cases illustrate the wide ranging clinical and pathological findings associated with this condition but both also have unusual features. The solitary plasma cell lesion had an exceptional 32 year clinical history and was associated with systemic amyloidosis of AL type. The multicentric hyaline vascular case was associated with coexistent multiple myeloma and amyloid deposition also of $\mathrm{AL}$ type. These cases are presented with a review of the relevant literature.
\end{abstract}

\section{Introduction}

Angiofollicular lymph node hyperplasia (AFLNH) was first described in $1956 .{ }^{1}$ It was originally reported as a solitary mediastinal lesion but it has since been described in other sites. ${ }^{2}$ Multicentric involvement has also been reported.,.$^{3,4}$

AFLNH has been divided into two clinicopathological variants, the hyaline vascular type and the plasma cell type. ${ }^{5}$ The plasma cell type is less common and consists of hyalinization or hyperplasia of lymphoid follicles separated by sheets of plasma cells. There are frequent systemic manifestations including fever, anaemia and hypergammaglobulinaemia. These abate when the lesion is removed. The hyaline vascular type is characterized by small follicles with radially penetrating vessels separated by richly vascular interfollicular tissue. Transitional forms of AFLNH have also been described. $^{5}$

The multicentric form of the disease frequently has systemic manifestations and runs an aggressive clinical course with a fatal outcome. ${ }^{3,4,6}$ Furthermore, these patients run an increased risk of developing Kaposi's sarcoma and malignant lymphoma. ${ }^{4}$

We describe two cases of AFLNH, one solitary and one multicentric, that together demonstrate the broad histological and clinical spectrum of the disease.

\section{Case reports}

Case 1

A 55 year old Caucasian woman presented complaining of nausea, vomiting and chest pain. She had a past

Correspondence: K.P. West, B.Sc., M.B., Ch.B., M.R.C.Path. Accepted: 25 August 1988 history of an anterior mediastinal mass present of chest X-ray for 32 years. The presence of this mass wats subsequently confirmed by computerized tomography. Examination revealed complete heart block, cardiomegaly and hepatomegaly. Laboratory inves:gations were as follows: haemoglobin $9.8 \mathrm{~g} / \overline{\mathrm{A}}$, ESR $140 \mathrm{~mm} / \mathrm{h}$, potassium $6.1 \mathrm{mmol} / \mathrm{l}$, urea $23.5 \mathrm{mmol}$, creatinine $582 \mu \mathrm{mol} / 1$, albumin $30 \mathrm{~g} / \mathrm{l}$, serum imm globulin: IgG 25.7 g/l, IgM 2.88 g/l, IgA 3.50 g/l Ne serum paraprotein was identified and there weresno Bence Jones proteins in the urine. A bone marro biopsy contained $5 \%$ plasma cells. The patient w referred for biopsy of her mediastinal mass and dien suddenly 24 hours after surgery.

At autopsy a mass $6 \times 4 \times 4 \mathrm{~cm}$ was identified in the anterior mediastinum adjacent to the superior veri cava. This had a haemorrhagic cut surface with flecks of calcification. The heart weighed $450 \mathrm{~g}$, the myoca dium was pale and both ventricles were thickened. $T B$ kidneys each weighed $100 \mathrm{~g}$, had pale waxy cortices and pitted subcapsular surfaces. There was no other lymphadenopathy.

Microscopy of the mediastinal mass reveale lymphoid tissue in which small aggregates of lym phocytes were surrounded by sheets of plasma cels some of which appeared bizarre and binucleate Immunoperoxidase staining for immunoglobulin lig chains showed that these cells were polyclonal. The appearances were considered to represent the plasma cell variant of AFLNH. Lymph nodes elsewhere wefe unaffected.

Examination of the kidneys and heart revealed the presence of amyloid stainable by Congo Red. Amylod was also demonstrable on electron microscopy. Using potassium permanganate pretreatment the amylofa was found to be of AL type. Immunoglobulin light 


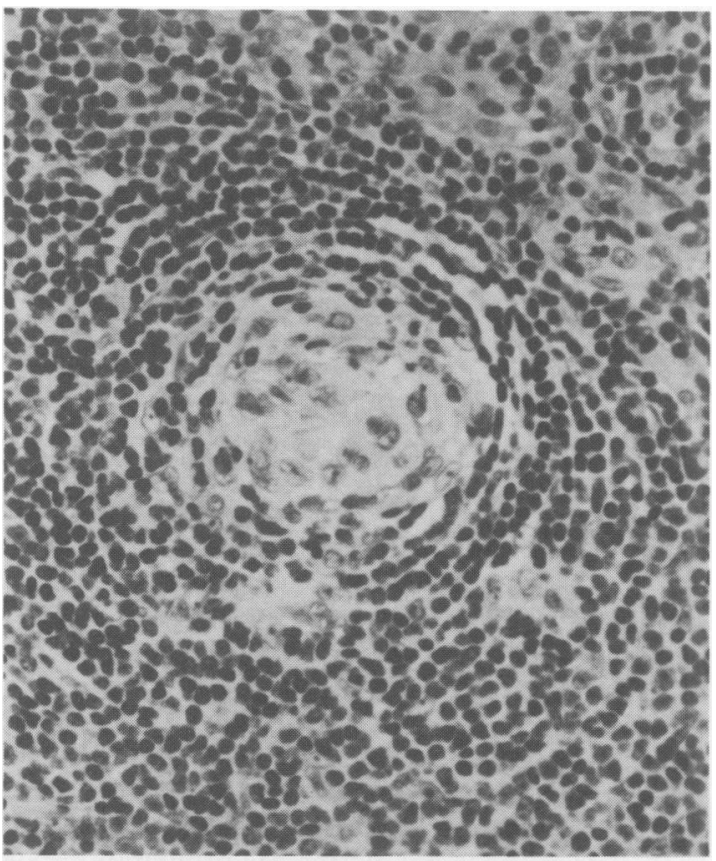

Figure 1 Case 2: follicle showing hyalinization and layering of small lymphoid cells (H \& E × 250).

chains could not, however, be demonstrated in the tissue available.?

\section{Case 2}

A 57 year old Caucasian male presented complaining of chest pain and weight loss of $7 \mathrm{~kg}$ in a 9 month period. Examination revealed right cervical and axillary lymphadenopathy and hepatosplenomegaly. Investigations were as follows: haemoglobin $13.9 \mathrm{~g} / \mathrm{dl}$, plasma viscosity $1.67 \mathrm{cP}$, potassium $5.0 \mathrm{mmol} / 1$, urea $10.6 \mathrm{mmol} / \mathrm{l}$, creatinine $139 \mu \mathrm{mol} / \mathrm{l}$, albumin $29 \mathrm{~g} / \mathrm{l}$. Plasma electrophoresis revealed a monoclonal IgA lambda band. Radiological examination demonstrated osteosclerotic lesions in vertebrae and ribs but no mediastinal mass was identified. A liver biopsy and vertebral biopsy were normal but axillary lymph node biopsy showed AFLNH of the hyaline vascular type (Figure 1).

Treatment with prednisolone was commenced but the patient continued to lose weight and was readmitted with papilloedema, neuropathy and a chest infection. Investigation at this time showed plasma sodium $119 \mathrm{mmol} / 1$, potassium $8.1 \mathrm{mmol} / 1$, urea $40 \mathrm{mmol} / 1$, creatinine $212 \mu \mathrm{mol} / \mathrm{l}$. Cerebrospinal fluid was sampled and the findings were consistent with GuillainBarré syndrome. The hyperkalaemia was treated with calcium-resonium and the chest infection with antibiotics. The neuropathy and papilloedema resolved spontaneously but there was a general deterioration with the development of profound hypoproteinaemia (albumin $19 \mathrm{~g} / \mathrm{l}$ ) and associated oedema, ascites and pleural effusions. The patient died 10 months after the initial presentation.

At autopsy enlarged lymph nodes up to $3.5 \mathrm{~cm}$ in diameter were found in the mediastinum, pulmonary hila, paratracheal, para-aortic and inguinal regions. The spleen weighed $490 \mathrm{~g}$ and had a uniform deep red cut surface. Hard pale osteosclerotic lesions were identified in the 12 th thoracic and 1 st lumbar vertebrae and softer pale nodules $3 \mathrm{~cm}$ across were identified in the 10 th and 11 th ribs on the right. Ascites, pericardial and pleural effusions were noted and there was marked pulmonary oedema.

Histological examination of lymph node biopsies from this patient showed the typical features of the hyaline vascular variant of AFLNH. Numerous small follicles were present, many with hyaline centres and radially penetrating vessels. The interfollicular tissue was highly vascular but plasma cells were not conspicuous.

Histological examination of lymph nodes from all sites at autopsy revealed marked autolysis but their appearances were consistent with AFLNH of hyaline vascular subtype. The spleen was histologically normal.

The bone marrow contained a monoclonal IgA

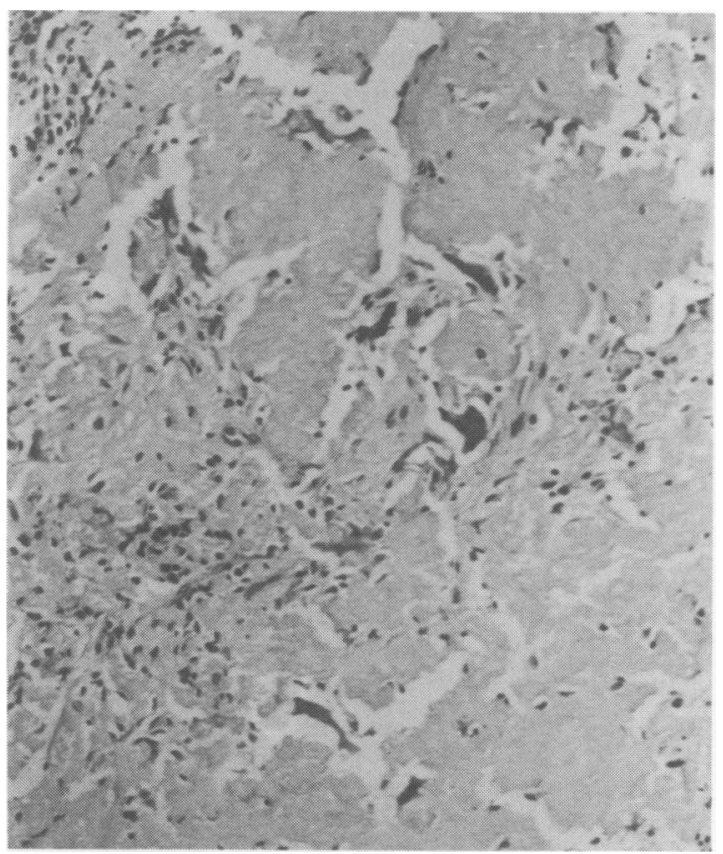

Figure 2 Case 2: nodule of amyloid from a rib including multinucleate giant cells (H \& E $\times 250$ ). 
lambda plasma cell proliferation in keeping with the patient's circulating paraprotein.

The osteosclerotic lesions consisted of thickened bony trabeculae which appeared similar to those of Paget's disease with prominent cement lines. The residual marrow spaces contained abundant plasma cells. The nodular lesions from the ribs consisted of large amounts of amyloid with associated multinucleate giant cells (Figure 2). This was found to be of AL type and stained positively for lambda light chain.

\section{Discussion}

The cases described exemplify the spectrum of clinical and pathological findings in AFLNH.

Case 1 is an example of the solitary plasma cell variant of the disease. This accounts for less than $10 \%$ of cases ${ }^{5}$ and it is often associated with a polyclonal hyperglobulinaemia and anaemia ${ }^{8}$ both of which were present in the case described. The apparent 32-year history in this case is, however, unusual.

The presence of amyloidosis in association with AFLNH is a rare but documented finding. ${ }^{9-11}$ One of the previous cases ${ }^{8}$ was of a mixed plasma cell and hyaline vascular type and the amyloid deposition was confined to the lesion itself and the spleen. The other two cases ${ }^{10,11}$ were of the solitary plasma cell type and in both there was systemic amyloidosis in association with nephrotic syndrome.

The origin of the amyloid material in AFLNH has been the subject of some discussion in the literature. Bonneau et al. ${ }^{9}$ and Chan et al. ${ }^{11}$ thought that it was of so called AA type. This is the form of amyloid seen in chronic reactive states and the fibrils are derived from serum amyloid A. ${ }^{12}$ Garcia-San Miguel et al. ${ }^{10}$ however, found amyloid of AL type in a case of AFLNH and it is this type of amyloid that was present in both of our cases. In AL amyloid the fibrils are derived from modified immunoglobulin light chains. ${ }^{12}$ Both of our patients had a source of excessive immunoglobulin production. Patient 1 had a polyclonal hyperglobulinaemia at the time of investigation and this may have been present for up to 32 years. The patient had no other demonstrable condition known to be associated with amyloidosis and its development appears to have been related to her AFLNH.

Case 2 is an example of the hyaline vascular type of AFLNH. This is the more common histological type but is uncommonly multicentric. ${ }^{8}$ Furthermore the associated manifestations in our case were more severe than those usually seen in hyaline vascular AFLNH. Weissenberger et al. ${ }^{4}$ studied 16 cases of multicentric AFLNH of which five were wholly or partly of the hyaline vascular type. All of these, in common with our case, had lymphadenopathy and one also had splenomegaly. Three complained of weight loss. One of their cases developed transient renal failure whion was also noted in our case. Gaba et al..$^{3}$ reported single case of AFLNH of hyaline vascular ty associated with peripheral neuropathy affecting particularly the lower limbs. A similar neuropathy was evident in case 2 . Recently ${ }^{13}$ a case of pseudotumoü cerebri has been reported in association with AFLNG in which transient papilloedema was seen. Paph loedema was also seen in case $2 .^{13}$

Patient 2 also had amyloidosis but was suffering from multiple myeloma and this, rather than AFLNE, may have been the underlying cause. It is interesting to note that the patient was producing a lambda paraprotein since lambda light chains are more commonty associated with amyloid deposition than are kappa light chains. ${ }^{12}$ Amyloidosis in conjunction with mu iple myeloma is recognized as having an unusu? distribution in comparison to other types. In partio ular tumorous deposits of amyloid in bone are well recognized. ${ }^{14}$

The association of myeloma and AFLNH is also unusual. Although lymphomas have been recorded the plasma cell population in AFLNH is usuali polyclonal. However, one group have described three cases with monoclonal plasma cell proliferations an one of these had a detectable paraprotein in tli serum. ${ }^{15}$ Furthermore the association of gamma hea chain disease and AFLNH has been demonstrateding patient with impaired $\mathrm{T}$ cell function. ${ }^{16}$

Bardwick et al. ${ }^{17}$ described the POEMS syndrome (polyneuropathy, organomegaly, endocrinopathy protein, skin changes) in which lymphadenopathy due to AFLNH is seen usually in association with the osteosclerotic type of multiple myeloma. Case $\mathscr{G}$ certainly showed clinical evidence of polyneuropath and a paraprotein and osteosclerotic lesions were present in association with myeloma. However, in th? case the AFLNH was of hyaline vascular type. whereas in other cases reported it has been of the plasma cell type. ${ }^{18}$

These cases represent two ends of a broad spectrum of disease that may be localized or multifocal io nature. In addition they provide an insight into some of the more unusual associations of this conditions Concerning the underlying cause of AFLNH the present cases are unable to throw further light on the suggestion of an association with immune deficiency states. Clearly there is much to be learnt by the long-term follow-up of AFLNH of all types in order t $\overline{\bar{R}}$ unravel the underlying histogenesis and pathogenesis of the condition.

\section{Acknowledgements}

The authors wish to acknowledge the assistance of the technical staff of the Bradford Royal Infirmary Departmen $\bar{D}$ of Histopathology and the secretarial and technical staff of the Leicester University Department of Pathology. 
1. Castleman, B., Iverson, L. \& Menendez, V. Localised mediastinal lymph node hyperplasia resembling thymoma. Cancer 1956, 9: 822-830.

2. Bugert, E., Gilchrist, G.S., Fairbanks, V.F., Lyn, H.B., Dukes, T.P. \& Harrison, E.G. Intra abdominal angiofollicular lymph node hyperplasia (plasma cell variant) with an erythropoietic factor. Mayo Clin Proc 1975, 50: 542-546.

3. Gaba, A.R., Stein, R.S., Sweet, D.L. \& Variakojis, D. Multicentric giant lymph node hyperplasia. Am J Clin Pathol 1978, 69: 86-90.

4. Weissenberger, D.D., Nathwani, B.N., Winberg, C.D. \& Rappaport, H. Multicentric angiofollicular lymph node hyperplasia: A clinicopathologic study of 16 cases. Hum Pathol 1985, 16: 162-172.

5. Keller, A.R., Hochholzer, L. \& Castleman, B. Hyaline vascular and plasma cell types of giant lymph node hyperplasia of the mediastinum and other locations. Cancer 1972, 29: 670-683.

6. Bartoli, E., Massarelli, G., Soggia, G. \& Tanda, F. Multicentric giant lymph node hyperplasia. A hyperimmune syndrome with a rapidly progressive course. $\mathrm{Am}$ J Clin Pathol 1980, 73: 423-426.

7. Wright, J.R., Calkins, E. \& Humphreys, R.L. Potassium permanganate reaction in amyloidosis. Lab Invest 1977 , 36: $274-281$.

8. Frizzera, G. Castleman's disease: more questions than answers. Hum Pathol 1985, 16: 202-205.

9. Bonneau, R., Paquin, F. \& Giroux, L. Angiofollicular lymph node hyperplasia of the plasma cell type with nephrotic syndrome and systemic amyloidosis: an unusual association. Lab Invest 1982, 46: 10A-11A.
10. Garcia-San Miguel, J., Rozman, C., Palacin, A. \& Nomdedeu, B. Mesenteric hyaline plasma cell lymph node hyperplasia with amyloid deposits. Arch Intern Med 1981, 141: 261-263.

11. Chan, W.C., Hargreaves, H. \& Keller, J. Giant lymph node hyperplasia with unusual clinicopathologic features. Cancer 1984, 53: 2135-2139.

12. Pepys, M.B. Amyloidosis; some recent developments. $Q J$ Med 1988, 67: 283-298.

13. Black, D.A., Forgacs, I., Davies, D.R. \& Thompson, R.P. Pseudotumour cerebri in a patient with Castleman's disease. Postgrad Med J 1988, 64: 217-219.

14. Lichtenstein, L. Plasma cell myeloma (multiple myeloma). In: Bone Tumours, 5th edition. C.V. Mosby, St Louis, 1977, pp. 288-317.

15. York, J.C., Taylor, C.R. \& Lukes, R.J. Monoclonality in giant lymph node hyperplasia. Lab Invest 1981, 44: 77A.

16. Okuda, K., Himeno, Y., Toyania, T., Ohta, N., Kitagawa, M. \& Sugai, S. Gamma heavy chain disease and giant lymph node hyperplasia in a patient with impaired T-cell function. Jpn J Med 1982, 21: 109-114.

17. Bardwick, P.A., Zvaifler, N.J., Gill, G.N., Newman, D., Greenway, G.D. \& Resnick, D.L. Plasma cell dysplasia with polyneuropathy, organomegaly, endocrinopathy, $M$ proteins and skin changes: The POEMS syndrome. Medicine (Baltimore) 1980, 59: 311-322.

18. Scully, R.E., Mark, E.J., McNeely, W.F. \& McNeely, B.U. Case records of the Massachusetts General Hospital, Case 10 - 1987. N Engl J Med 1987, 316: 606-618. 